\title{
PRESSUPOSTOS PARA A CONCEPÇÃO DE EDUCAÇÃO NO PENSAMENTO DE MARX: UM ESTUDO DE 1844 A 1848
}

\author{
SUPUESTOS PARA LA CONCEPCIÓN DE LA EDUCACIÓN EN EL PENSAMIENTO DE \\ MARX: UN ESTUDIO DE 1844 A 1848
}

\section{ASSUMPTIONS FOR THE CONCEPTION OF EDUCATION IN MARX'S THOUGHT: A STUDY FROM 1844 TO 1848}

\author{
DOI: http://doi.org/10.9771/gmed.v13i3.44709
}

\author{
José Salvador Almeida ${ }^{1}$ \\ Frederico Jorge Ferreira Costa ${ }^{2}$
}

\begin{abstract}
Resumo: O objetivo do presente estudo é identificar a concepção de educação em Marx, no período de 1844 a 1848, a partir dos Manuscritos econômico-filosóficos (1844), da A ideologia alemã (1845-1846) e do Manifesto Comunista (1848). A pesquisa possui abordagem qualitativa exploratória, com o emprego do procedimento bibliográfico. Identificou-se que a concepção de educação em Marx, depende da análise de pressupostos que compõem sua teoria crítica, em especial a crítica à economia nacional e a propriedade privada, o trabalho estranhado, a crítica à sociedade capitalista, e a afirmação marxiana do ser genérico. Após a análise dos pressupostos, defendemos que Marx entende a educação como um processo de desenvolvimento das capacidades físicas, intelectuais e moral do ser humano em geral, uma educação que é indissociável da sociedade, pois articula-se social e historicamente com a categoria trabalho, na acepção de atividade constitutiva e formativa do ser social.
\end{abstract}

Palavras-chave: Educação. Marx. Trabalho. Capitalismo. Homem.

Resumen: El objetivo de este estudio es identificar la concepción de la educación de Marx, en el período 1844 a 1848, a partir de los Manuscritos económico-filosóficos (1844), La ideología alemana (1845-1846) y el Manifiesto Comunista (1848). La investigación tiene un enfoque cualitativo exploratorio, utilizando el procedimiento bibliográfico. Se identificó que la concepción de la educación de Marx depende del análisis de los supuestos que componen su teoría crítica, especialmente la crítica a la economía nacional y la propiedad privada, el trabajo enajenado, la crítica a la sociedad capitalista y la afirmación marxista de ser genérico. Tras analizar los supuestos, defendemos que Marx entiende la educación como un proceso de desarrollo de las capacidades físicas, intelectuales y morales del ser humano en general, una educación que es inseparable de la sociedad, ya que se articula social e históricamente con la categoría de trabajo, en el sentido de la actividad constitutiva y formativa del ser social.

Palabras clave: Educación. Marx. Trabajo. Capitalismo. Hombre.

Abstract: The aim of this study is to identify Marx's conception of education, in the period 1844 to 1848, based on the Economic-Philosophical Manuscripts (1844), The German Ideology (1845-1846) and the Communist Manifesto (1848). The research has an exploratory qualitative approach, using the bibliographic procedure. It was identified that Marx's conception of education depends on the analysis of assumptions that make up his critical theory, especially the critique of the national economy and private property, estranged work, the critique of capitalist society, and the Marxian affirmation of being generic. After analyzing the assumptions, we defend that Marx understands education as a process of development of the physical, intellectual and moral capacities of human beings in general, an education that is inseparable from society, as it is socially and historically articulated with the category of work, in the sense of the constitutive and formative activity of the social being.

Keywords: Education. Marx. Work. Capitalism. Man. 


\section{Introdução}

Marx não elaborou um tratado específico e rigoroso sobre a temática da educação ${ }^{3}$, porém, é notório, no conjunto de suas obras, a preocupação dispensada por esse grande pensador materialista sobre a questão do ensino, da educação e da formação humana em geral.

$\mathrm{Na}$ nossa compreensão, Marx não possui preocupações com formulações abstratas, isto é, com devaneios que são possíveis somente no campo da imaginação. Ele parte do real, do concreto, das contradições, do existente, logo, parte de homens reais, vivos, que respiram e que estão em relação com outros homens reais e concretos que vivem numa determinada forma de organização social. Neste sentido, defendemos que tal compreensão é de muita importância para entender os conceitos e as categorias que estão presentes no pensamento de Marx, principalmente, a concepção de educação que tentaremos apresentar.

No que se refere à concepção de educação em Marx 4 , percebe-se que as formulações acerca deste campo de estudo estão diretamente articuladas com a severa crítica de Marx ao modo de produção capitalista. Portanto, asseveramos, mais uma vez, que não há sentido falar sobre a questão da educação em Marx de forma abstrata, isto é, idealizada, sem articulação com as contradições do real, ou melhor, como um conceito independente do objeto.

A visão de Marx sobre educação, neste estudo, deve ser compreendida observando o contexto histórico do século XIX, em especial, a partir dos seguintes pressupostos, a saber: 1) a crítica de Marx à economia nacional e a propriedade privada; 2) o conceito de trabalho estranhado; 3) a crítica de Marx à sociedade capitalista e 4) a afirmação de Marx de que o homem é um ser genérico. Assim, tais pressupostos nortearão nosso entendimento sobre a concepção de educação em Marx, de 1844 a 1848 , que se encontra de maneira implícita nas obras analisadas.

\section{Crítica à economia nacional e a propriedade privada: implicações para o entendimento sobre a concepção de educação em Marx}

Em profundo debate com os economistas (Jean Baptiste Say (1767-1832), Jean Charles Léonard Simonde de Sismondi (1773-1842), Frédéric Skarbek (1792-1866), Adam Smith (1723-1790) e David Ricardo (1772-1823) da economia nacional, Marx apresenta sua crítica contra esses teóricos que buscavam fundamentar o modo capitalista de produção.

Diante dessa informação, perguntamos, então, em que consiste tal crítica de Marx contra os pressupostos da economia nacional? Qual a sua relação com a educação?

Nos Manuscritos econômico-filosóficos (1844) diz Marx:

Ao leitor familiarizado com a economia nacional não preciso assegurar que meus resultados foram obtidos mediante uma análise inteiramente empírica, fundada num meticuloso estudo crítico da economia nacional. É óbvio que utilizei, além dos socialistas franceses e ingleses, também trabalhos socialistas alemães. No entanto, os 
trabalhos alemães plenos de conteúdo (Inhaltsvollen) e originais nesta ciência reduzem-se fora os escritos de Weitling - aos estudos publicados por Hess nas "Vinte e uma folhas de impressão" (Einundzwanzing Bogen) e aos "Umrisse zur Kritik der National ökonomie", de Engels, publicados nos "Anais franco-alemães", nos quais eu indicara igualmente, de modo bem geral, os primeiros elementos do presente trabalho. (MARX, 2010, p. 19-20).

Marx desenvolve uma crítica contra a economia nacional, ciência fundamentadora do capitalismo, a partir de uma análise inteiramente empírica, ou seja, de um estudo meticuloso do processo da vida real, pois, ao verificar que a economia nacional parte do fato dado e acabado da propriedade privada $^{5}$, sem apresentar uma explicação satisfatória para o mesmo, Marx inicia um profundo debate teórico com os pensadores citados a fim de provar as contradições existentes entre suas leis e teorias (formulações arbitrárias) e a vida real, material e concreta dos homens.

Marx assevera que a economia nacional percebe o processo material da propriedade privada, que passa, na realidade, por fórmulas gerais, abstratas, que passam a valer como leis para ela. Para o pensador alemão, a economia nacional não concebe estas leis, isto é, não mostra como têm origem na essência da propriedade privada. Ainda, de acordo com Marx, a economia nacional não apresenta nenhum esclarecimento no que diz respeito ao fundamento da divisão entre trabalho e capital, entre capital e terra (MARX, 2010, p. 79).

Assim, diante do exposto, em tom bastante crítico, diz Marx: "Não nos desloquemos, como [faz] o economista nacional quando quer esclarecer [algo], a um estado primitivo imaginário" (MARX, 2010, p. 80). Pois, para Marx, um estado primitivo imaginário nada explica.

Durante seu processo de análise empírica, Marx afirma, sem hesitação: "Nós partimos de um fato nacional-econômico, presente" (MARX, 2010, p. 80).

Explica, portanto, Marx:

O trabalhador se torna tanto mais pobre quanto mais riqueza produz, quanto mais a sua produção aumenta em poder e extensão. $\mathrm{O}$ trabalhador se torna uma mercadoria tão mais barata quanto mais mercadorias cria. Com a valorização do mundo das coisas (Sachenwelt) aumenta em proporção direta a desvalorização do mundo dos homens (Menschenwelt). O trabalho não produz somente mercadorias; ele produz a si mesmo e ao trabalhador como uma mercadoria, e isto na medida em que produz, de fato, mercadorias em geral. (MARX, 2010, p. 80).

Ao denunciar essa forma de trabalho, nociva ao ser humano, pois, na sociedade capitalista, segundo Marx, o trabalho não produz somente mercadorias, ele produz a si mesmo e ao trabalhador como uma mercadoria, na medida em que produz de fato mercadorias em geral. Ou seja, o próprio trabalhador se torna uma mercadoria, perdendo, então, suas qualidades humanas, deixando de viver no mundo verdadeiro dos homens para viver num mundo das mercadorias, em outras palavras, um mundo com mercadorias personificadas e homens coisificados. Assim, entendemos que a crítica à economia nacional e, principalmente, a propriedade privada é muito importante para entender a concepção de educação em Marx, pois, aqui, percebe-se a preocupação deste pensador, materialista, ao denunciar a valorização do mundo das mercadorias em detrimento da desvalorização do mundo dos homens. Portanto, entendemos que, na sociedade capitalista, o homem é levado a condição de mercadoria e a mercadoria é levada a uma 
condição superior ao homem, pois a mercadoria domina o campo das relações sociais. Ao formular essa crítica, entende-se que Marx está preocupado com um mundo criado pelo homem e para o homem.

Nesta forma de sociedade, o trabalhador só é visto como trabalhador na medida em que ele está numa relação direta com o capital, ou melhor, quando o trabalhador está empregado e recebe um salário para sobreviver (garantir a sua dupla sobrevivência como sujeito físico e como trabalhador). A vida do homem (trabalhador), no capitalismo, para poder existir depende, exclusivamente, do capitalista, pois o homem fora da relação do trabalho (emprego), simplesmente, não existe, uma vez que não recebe salário e, portanto, não possui dinheiro para comprar mercadorias. Logo, neste sentido, conclui-se que, 1) se o homem (trabalhador) possui trabalho (emprego), então, vive, pois recebe salário; 2) se o homem (trabalhador) não possui trabalho (emprego), então, perece, pois não recebe salário.

$\mathrm{Na}$ primeira parte da obra, a saber: $A$ ideologia alemã (1845-1846), Marx e Engels reconhecem o movimento revolucionário da grande indústria, realizado pela burguesia e, na ocasião, adverte que essas forças produtivas, sob o regime da propriedade privada, obtêm apenas um desenvolvimento unilateral, convertem-se para a maioria em forças destrutivas e uma grande quantidade dessas forças não consegue alcançar a menor utilização na propriedade privada, isto é, a grande maioria passa a viver sem propriedade privada, constituindo-se, assim, a classe dos proletários, que vivem em condições degradantes e desumanas, conforme acusam Marx e Engels, em várias passagens de suas obras. É importante destacar, ainda, que, para Marx e Engels, a grande indústria torna insuportável não somente a relação do trabalhador com o capitalista, mas a própria relação do trabalhador com o trabalho que passa a se configurar, na nossa compreensão, como algo hostil, nocivo e estranho, ou seja, como atividade imposta, de tal forma que o trabalhador não se reconhece na sua própria atividade.

$\mathrm{Na}$ passagem abaixo, retirada também da primeira parte da obra A ideologia alemã (1845-1846), Marx e Engels chamam atenção para as condições existentes que antecipam o modo de produção que os indivíduos devem apreender para reprodução da sua própria vida.

\footnotetext{
O modo pelo qual os homens produzem seus meios de vida depende, antes de tudo, da própria constituição dos meios de vida já encontrados e que eles têm de reproduzir. Esse modo de produção não deve ser considerado meramente sob o aspecto de ser a reprodução da existência física dos indivíduos. Ele é, muito mais, uma forma determinada de sua atividade, uma forma determinada de exteriorizar sua vida, um determinado modo de vida desses indivíduos. Tal como os indivíduos exteriorizam sua vida, assim são eles. O que eles são coincide, pois, com sua produção, tanto com $o$ que produzem como também com o modo como produzem. O que os indivíduos são, portanto, depende das condições materiais de sua produção. (MARX; ENGELS, 2007, p. 87).
}

Percebemos, então, que existe uma relação inevitável entre a vida dos indivíduos e o modo pelo qual eles produzem os seus meios de vida. Tal modo de produção, segundo Marx e Engels, que não deve ser considerado apenas sob o aspecto de ser a reprodução da existência física dos indivíduos é, além disso, uma forma determinada de sua atividade, uma forma determinada de exteriorizar a sua própria vida, ele é um determinado modo de vida desses indivíduos, de tal forma que, na nossa compreensão, não podemos separar o que os indivíduos são do seu modo de produção. 
Já no Manifesto Comunista (1848), na primeira parte (I - Burgueses e Proletários), Marx e Engels afirmam:

Todas as classes que no passado conquistaram o poder trataram de consolidar a situação adquirida submetendo toda a sociedade às suas condições de apropriação. Os proletários não podem apoderar-se das forças produtivas sociais senão abolindo o modo de apropriação existente até hoje. Os proletários nada têm de seu a salvaguardar; sua missão é destruir todas as garantias e seguranças da propriedade privada até aqui existentes. (MARX; ENGELS, 2007, p. 50).

Neste documento político (Manifesto Comunista), Marx e Engels apresentam, com riqueza de detalhes, a condição da situação do trabalhador na sociedade capitalista moderna, uma sociedade totalmente nociva ao desenvolvimento pleno do ser humano, pois tal forma de sociedade é fundamentada na propriedade privada e no trabalho (estranhado) que originam as mais profundas desigualdades entre os homens. Para Marx e Engels, nessa forma de sociedade, o trabalhador torna-se um indigente e o pauperismo cresce ainda mais rapidamente do que a população e a riqueza (MARX; ENGELS, 2007, p. $50)$.

Nos Manuscritos econômico-filosóficos (1844), Marx afirma que “a economia nacional conhece o trabalhador apenas como animal de trabalho, como uma besta reduzida às mais estritas necessidades corporais" (MARX, 2010, p. 31). Ele apresenta como a economia nacional considera o trabalho nas seguintes linhas esclarecedoras:

A economia nacional considera o trabalho abstratamente como uma coisa; o trabalho é uma mercadoria: se o preço é alto, a mercadoria é muito procurada; se é baixo, [a mercadoria] é muito oferecida; como mercadoria, o trabalho deve baixar cada vez mais de preço: o que força a isso é em parte a concorrência entre capitalista e trabalhador, em parte a concorrência entre trabalhadores; ... (MARX, 2010, p. 35-36).

Entendemos, portanto, neste estudo, que a crítica de Marx à economia nacional e, principalmente, a propriedade privada é um importante pressuposto para a compreensão da concepção de educação marxiana. Pois, conforme já colocamos, embora não exista um tratado sobre a temática da educação, em Marx, é possível encontrar princípios, no conjunto da obra, que fundamentam uma concepção de educação voltada para a realização plena de todas as capacidades humanas.

\section{O trabalho estranhado e a relação com a concepção de educação no pensamento de Marx}

Neste artigo, defendemos que Marx expõe sua teoria sobre o trabalho estranhado nos Manuscritos econômico-filosóficos (1844), especificamente, no final do primeiro manuscrito intitulado "Trabalho estranhado e propriedade privada", após uma longa exposição acompanhada de um estudo crítico das categorias econômicas elaboradas pela economia nacional.

Na obra, Marx apresenta, em caráter revelador, as consequências nefastas do estranhamento na essência do trabalho e suas implicações para o desenvolvimento pleno das capacidades humanas. Pois, para este pensador alemão, na sociedade capitalista, sem dúvida, o trabalhador baixa a condição da mais miserável mercadoria e o seu preço está totalmente relacionado aos custos de sua produção. A atividade vital humana aparece no capitalismo apenas sob a forma de emprego. Assim, nessa condição, o homem 
passa a viver em função de um mero trabalho (emprego), de tal forma que, quando ele se encontra fora da relação do trabalho, ele não existe para a economia nacional.

Nesse Manuscrito (Trabalho estranhado e propriedade privada), Marx examina, inicialmente, o estranhamento da atividade humana prática, o trabalho, sob dois aspectos, a saber: 1) A relação do trabalhador com o produto do trabalho como objeto estranho e poderoso sobre ele [trabalhador]. Para Marx, esta relação é ao mesmo tempo a relação com o mundo exterior sensível, ou seja, com os objetos da natureza como um mundo alheio [não pertencente ao trabalhador] que se lhe defronta hostilmente. 2) A relação do trabalho com ato da produção no interior do trabalho. Segundo Marx, esta relação é a relação do trabalhador com a sua própria atividade como uma atividade estranha, isto é, não pertencente ao trabalhador. Aqui, percebe-se que, a atividade se manifesta como miséria, a força como impotência, a procriação como castração. Diz Marx: "A energia espiritual e física própria do trabalhador, a sua vida pessoal - "pois o que é vida senão atividade" - como uma atividade voltada contra ele mesmo, independente dele, não pertencente a ele. [...]" (MARX, 2010, p. 83).

Após examinar o estranhamento da atividade humana prática sob esses dois aspectos, Marx afirma que na medida em que o trabalho estranhado 1) estranha do homem a natureza, 2) e o homem de si mesmo, de sua própria função ativa, de sua atividade vital; ele estranha do homem o gênero [humano]. Faz-lhe da vida genérica apenas um meio da vida individual. Segundo Marx, o trabalho estranhado faz, por conseguinte: 3) do ser genérico do homem, tanto da natureza quanto da faculdade genérica espiritual dele, um ser estranho a ele, um meio da sua existência individual. Pois, o trabalho estranhado estranha do homem o próprio corpo, assim como estranha do homem a natureza fora dele, tal como a sua essência espiritual, a sua essência humana. 4) uma consequência imediata de o homem estar estranhado do produto do seu trabalho, de sua própria atividade vital e de seu ser genérico é o estranhamento do homem pelo próprio homem. Pois, Marx assevera que quando o homem está frente a si mesmo, defronta-se com ele o outro homem (MARX, 2010, p. 85-86). Assim, esclarece o autor: “O que é produto da relação do homem com o seu trabalho, produto de seu trabalho e consigo mesmo, vale como relação do homem com outro homem, como o trabalho e o objeto do trabalho de outro homem" (MARX, 2010, p. 86).

Marx desenvolve, então, sua concepção sobre a categoria trabalho diferente da concepção desenvolvida pela economia nacional. Pois, entendemos que, para Marx, o trabalho (atividade humana prática) deve proporcionar uma relação de reconhecimento entre o trabalhador e o objeto por ele produzido, portanto, diferente da relação produzida pelo trabalho estranhado, de tal forma que o trabalhador tenha domínio sobre esta relação. Nesse domínio, o trabalhador deve, além de se reconhecer no objeto, também dominá-lo e não ser dominado pelo objeto. Isto posto, deduzimos e afirmamos que a verdadeira relação do homem com os objetos exteriores a ele se daria numa relação de reconhecimento e não de estranhamento. A atividade humana prática (trabalho), portanto, deve estar a serviço do desenvolvimento pleno das capacidades humanas e pertencer totalmente ao homem na condição de atividade humana de autodesenvolvimento e autoformação.

Defendemos, neste estudo, que se encontra implícito, no pensamento de Marx, em especial, no manuscrito "Trabalho estranhado e propriedade privada", localizado nos Manuscritos econômico-filosóficos 
(1844), a relação entre o trabalho estranhado com a sua concepção de educação, visto que, ao revelar que o trabalho nas condições impostas pela sociedade capitalista impede o desenvolvimento pleno das capacidades humanas, Marx fundamenta, assim, a relação necessária entre o trabalho (fundamento ontológico de constituição do ser social) e a educação para o desenvolvimento pleno das capacidades humanas. Desse modo, uma relação muito diferente da relação imposta pela lógica do capital. Vejamos, então, melhor este argumento.

Analisando a realidade social, Marx explica como a efetivação do trabalho aparece ao estado nacional-econômico.

\begin{abstract}
A efetivação do trabalho tanto aparece como desefetivação que o trabalhador é desefetivado até morrer de fome. A objetivação tanto aparece como perda do objeto que o trabalhador é despojado dos objetos mais necessários não somente à vida, mas também dos objetos do trabalho. Sim, o trabalho mesmo se torna um objeto, do qual o trabalhador só pode se apossar com os maiores esforços e com as mais extraordinárias interrupções. A apropriação do objeto tanto aparece como estranhamento (Entfremdung) que, quanto mais objetos o trabalhador produz, tanto menos pode possuir e tanto mais fica sob o domínio do seu produto, do capital. (MARX, 2010, p. 80-81).
\end{abstract}

O que deveria ser, portanto, a efetivação do trabalhador, torna-se, então, desefetivação, uma vez que o trabalhador não se reconhece no produto do seu próprio trabalho. Desse modo, na sociedade do capital, o trabalho estranhado torna-se um empecilho para o autodesenvolvimento humano e social, pois não desenvolve o homem. Tal forma específica de trabalho atrofia o trabalhador, visto que se torna algo nocivo e pernicioso ao próprio trabalhador.

No capitalismo ${ }^{6}$, o trabalhador não possui liberdade para produzir. Este produz sob as determinações de outro homem, estranho a ele. O trabalhador não possui os objetos mais necessários para a realização do trabalho, pois estes objetos foram historicamente expropriados. Assim, entendemos que a tese da união da educação com a produção material, defendida por Marx e Engels, em meados de 1848, no Manifesto Comunista (1848), é necessária para a retomada consciente e responsável do homem sobre o processo do trabalho (atividade consciente livre), isto é, que tal união (educação e produção material) deve contribuir no processo de desalienação dos homens em relação ao produto do seu trabalho, ao processo de produção, ao ser genérico do homem e ao outro homem.

Diante da exposição acima, defendemos que a educação possui um papel relevante e uma conexão, direta e necessária, com o trabalho produtivo, criador de valores de uso, uma vez que entendemos que é impossível pensar a construção de uma nova sociedade humana sem refletir sobre a socialização dos valores produzidos historicamente. Neste sentido, reforçamos que a educação, para Marx, deve ser entendida também como uma atividade formativa responsável pelo desenvolvimento pleno das capacidades humanas.

\title{
A crítica de Marx à sociedade capitalista e a defesa de uma educação verdadeiramente humana e social
}

Nos Manuscritos econômico-filosóficos (1844), Marx afirma que o salário é determinado mediante o confronto hostil entre o capitalista e o trabalhador. Afirma, ainda, que neste confronto a necessidade da 
vitória pertence ao capitalista. Visto que o capitalista pode viver mais tempo sem o trabalhador do que o trabalhador sem o capitalista.

[...] [A] aliança entre os capitalistas é habitual e produz efeito; [a] dos trabalhadores é proibida e de péssimas consequências para eles. Além disso, o proprietário fundiário e o capitalista podem acrescentar vantagens industriais aos seus rendimentos, [ao passo que] o trabalhador [não pode acrescentar] nem renda fundiária, nem juro do capital (Capitalinteresse) ao seu ordenado industrial. Por isso [é] tão grande a concorrência entre os trabalhadores. Portanto, somente para o trabalhador a separação de capital, propriedade da terra e trabalho é uma separação necessária, essencial e perniciosa. Capital e propriedade fundiária não precisam estacionar nessa abstração, mas o trabalho do trabalhador, sim. (MARX, 2010, p. 23-24).

Percebe-se que o trabalhador sempre ficará em desvantagem nesse confronto hostil com o capitalista, uma vez que nada é acrescentado ao salário do trabalhador, como, por exemplo, juros e outras vantagens adicionais sobre o salário. Assim, somente para o trabalhador a separação de capital, propriedade da terra e trabalho é uma separação necessária, essencial e perniciosa.

Utilizando uma citação de Adam Smith, Marx afirma que a taxa mais baixa e unicamente necessária para o salário é a subsistência do trabalhador durante o trabalho, e ainda o bastante para que ele possa sustentar sua família e para que a raça dos trabalhadores não se extinga. Diz Marx: "O salário habitual é, segundo Smith, o mais baixo que é compatível com a simples humanidade (simple humanité), isto é, com uma existência animal" (MARX, 2010, p. 24).

Afirmamos que Marx se recusa a aceitar as determinações impostas pela economia nacional que fundamentam a sociedade capitalista, pois, como já explicamos, tal sociedade é nociva ao ser humano. Nesta forma de organização social, o homem passa a viver somente em função de um trabalho (emprego) cuja finalidade é a mera ampliação da riqueza, principalmente, para o capitalista. Isto posto, reafirmamos que Marx considera o trabalho nessas condições como pernicioso, funesto e nocivo ao ser humano.

No Manifesto Comunista (1848), um documento histórico e político, após desenvolver a tese de que “A história de todas as sociedades até hoje existente é a história das lutas de classes" e, na oportunidade, depois de uma longa e demorada exposição sobre o processo revolucionário realizado pela burguesia moderna, que brotou das ruínas da sociedade feudal e não aboliu os antagonismos de classe, Marx e Engels afirmam:

Com o desenvolvimento da burguesia, isto é, do capital, desenvolve-se também o proletariado, a classe dos operários modernos, os quais só vivem enquanto têm trabalho e só têm trabalho enquanto seu trabalho aumenta o capital. Esses operários, constrangidos à vender-se a retalho, são mercadoria, artigo de comércio, como qualquer outro; em consequência, estão sujeitos a todas as vicissitudes da concorrência, e a todas as flutuações do mercado. (MARX; ENGELS, 2007, p. 46).

Ainda, de acordo com Marx e Engels, o crescente emprego de máquinas e a divisão do trabalho despojaram a atividade do operário do seu caráter autônomo, tirando-lhe todo o atrativo (MARX; ENGELS, 2007, p. 46). O operário passa a ter uma relação de dependência com o dono da fábrica, pois, este último possui, agora, as ferramentas e a matéria-prima, ou seja, os meios de produção para a realização da atividade do trabalhador. Neste sentido, explicam Marx e Engels: 
[...] O operário torna-se um simples apêndice da máquina e dele só se requer o manejo mais simples, mais monótono, mais fácil de aprender. Desse modo, o custo do operário se reduz, quase exclusivamente, aos meios de subsistência que lhe são necessários para viver e perpetuar sua espécie. Ora, o preço do trabalho, como de toda mercadoria é igual ao seu custo de produção. Portanto, à medida que aumenta o caráter enfadonho do trabalho, decrescem os salários. Mais ainda, na mesma medida em que aumenta a maquinaria e a divisão do trabalho, sobe também a quantidade de trabalho, quer pelo aumento das horas de trabalho, quer pelo aumento do trabalho exigido num determinado tempo, quer pela aceleração do movimento das máquinas etc. (MARX; ENGELS, 2007, p. 46).

Os autores do Manifesto Comunista (1848) afirmam que "a história de toda a sociedade até nossos dias moveu-se em antagonismos de classes, antagonismos que se têm revestido de formas diferentes nas diferentes épocas" (MARX; ENGELS, 2007, p. 57). Eles acreditam que a exploração de uma parte da sociedade por outra é um fato comum a todos os séculos anteriores.

\footnotetext{
Mas qualquer que tenha sido a forma assumida, a exploração de uma parte da sociedade por outra é um fato comum a todos os séculos anteriores. Portanto, não é de se espantar que a consciência social de todos os séculos, apesar de toda sua variedade e diversidade, se tenha movido sempre sob certas formas comuns, formas de consciência que só se dissolverão completamente com o desaparecimento total dos antagonismos de classe. (MARX; ENGELS, 2007, p. 57)
}

Portanto, para Marx e Engels, a revolução comunista é a ruptura mais radical com as relações tradicionais de propriedade; não admira, portanto, que no curso de seu desenvolvimento se rompa do modo mais radical, com as ideias tradicionais (MARX; ENGELS, 2007, p. 57).

Ao reivindicar a "ação prática revolucionária do homem social", Marx não tem intenção de reformar ou de melhorar a sociedade capitalista. Logo, entendemos que, para este pensador alemão, tal forma de sociedade é irreformável, uma vez que não se sustenta sem a produção da miséria, do pauperismo, do embrutecimento humano, da deformação do homem e de todas as formas de violência contra o ser humano.

Para Marx e Engels, “a primeira fase da revolução operária é a elevação do proletariado a classe dominante, a conquista da democracia” (MARX; ENGELS, 2007, p. 58). Na primeira fase, portanto, o proletariado deve avançar sobre a burguesia.

O proletariado utilizará sua supremacia política para arrancar pouco a pouco todo o capital da burguesia, para centralizar todos os instrumentos de produção nas mãos do Estado, isto é, do proletariado organizado como classe dominante, e para aumentar o mais rapidamente possível o total das forças produtivas. (MARX; ENGELS, 2007, p. 58).

Ainda, de acordo com Marx e Engels, isso só poderá ser realizado por intervenções despóticas, isto é, intervenções autoritárias e arbitrárias no direito de propriedade e nas relações de produções burguesas que deveriam ser realizadas por meio de aplicação de medidas que, do ponto de vista econômico, parecerão insuficientes e insustentáveis, mas que no desenrolar do movimento ultrapassarão a si mesmas e serão indispensáveis para transformar radicalmente todo o modo de produção (MARX; ENGELS, 2007, p. 58). 
Marx e Engels, dessa forma, apresentam, na segunda parte do Manifesto Comunista (1848), 10 (dez) medidas a fim de contribuir com a derrubada da supremacia da burguesia e, no mesmo escrito, advertem que tais medidas serão diferentes nos diferentes países.

Vejamos, então, as medidas indicadas pelos autores do Manifesto Comunista (1848).

1. Expropriação da propriedade fundiária e emprego da renda da terra para as despesas do Estado; 2. Imposto fortemente progressivo; 3. Abolição do direito de herança; 4. Confisco da propriedade de todos os emigrados e rebeldes; 5 . Centralização do crédito nas mãos do Estado por meio de um banco nacional com capital do Estado e com o monopólio exclusivo; 6. Centralização de todos os meios de comunicação e transporte nas mãos do Estado; 7. Multiplicação das fábricas nacionais e dos instrumentos de produção, arroteamento das terras incultas e melhoramento das terras cultivadas, segundo um plano geral; 8. Unificação do trabalho obrigatório para todos, organização de exércitos industriais, particularmente para a agricultura; 9. Unificação dos trabalhos agrícolas e industrial; abolição gradual da distinção entre a cidade e o campo por meio de uma distribuição mais igualitária da população pelo país; 10. Educação pública e gratuita a todas as crianças; Abolição do trabalho das crianças nas fábricas, tal como é praticado hoje. Combinação da educação com a produção material etc. (MARX; ENGELS, 2007, p. 58).

Na décima e última medida, Marx e Engels defendem, como se vê, a educação pública e gratuita para todas as crianças, ou seja, não somente para os filhos da classe operária, mas, é importante frisar, "para todas as crianças", bem como a abolição do trabalho das crianças nas fábricas tal como era praticado naquele contexto. Por fim, apresentam a tese, a saber: combinação da educação com a produção material7.

Diante do exposto, perguntamos, então, quais as motivações dessa medida? Por que defender a educação pública e gratuita para todas as crianças e não somente para os filhos da classe operária? Qual a concepção de educação para Marx?

Numa tentativa de responder às questões colocadas acima, afirmamos que a defesa da educação pública e gratuita para todas as crianças é uma medida que possui articulação direta com a emancipação da sociedade de classes e com a emancipação dos homens. Na nossa compreensão, tais princípios fundamentam a concepção de educação defendida por Marx, uma forma de educação que se contrapõe a lógica reprodutora do capital.

Defendemos ainda que a concepção de educação em Marx deve ser entendida como um processo de desenvolvimento das capacidades físicas, intelectuais e moral do ser humano em geral, visando à harmonia social entre o indivíduo e a coletividade, uma educação de desenvolvimento e aperfeiçoamento de todas as capacidades humanas.

No final do texto da décima medida, a tese apresentada por Marx e Engels traz outro princípio importantíssimo para compreender a concepção de educação no pensamento de Marx. Ao defender a combinação da educação com a produção material, Marx e Engels não pensam uma educação separada do modo de produção social, pois entendemos que estes pensadores negam a atual forma histórica de trabalho (trabalho estranhado) para afirmar o trabalho como condição ontológica de formação do ser social, embora o trabalho na condição ontológica também esteja presente no trabalho estranhado, porém, é importante lembrar, que este se encontra sob o domínio do capital. O que quer dizer que não existe uma concepção unilateral sobre o trabalho em Marx e Engels. Há, pois, uma concepção dialética sobre o 
trabalho. Então, desse modo, a articulação entre educação e produção material deveria ocorrer de maneira diferente das atuais condições estabelecidas pela sociedade do capital.

\section{A genericidade do homem e a relação com a concepção de educação no pensamento de Marx}

A afirmação categórica de que o homem é um ser genérico está desenvolvida no final do primeiro manuscrito dos Manuscritos econômico-filosóficos (1844). Este documento, intitulado "Trabalho estranhado e propriedade privada", fornece as bases para a compreensão da diferença primordial entre o homem e os demais animais e, no ensejo, afirma, por um lado, o trabalho como condição ontológica de constituição do ser social.

De acordo com Marx, o homem é um ser genérico, não somente quando faz na teoria e na prática do gênero, do seu próprio gênero, assim como do restante das coisas o seu objeto, mas também quando se relaciona consigo mesmo como gênero vivo, presente, quando se relaciona consigo mesmo como um ser universal e, portanto, livre (MARX, 2010, p. 83-84).

Para Marx, existe algo em comum entre a vida genérica do homem e do animal, pois o homem assim como o animal vive da natureza inorgânica, porém quanto mais universal é o homem em relação ao animal, tanto mais universal é o domínio da natureza inorgânica da qual ele vive. O autor entende que fisicamente o homem vive somente dos produtos da natureza, ou melhor, que o homem nada pode criar sem a natureza, sem o mundo exterior sensível. Logo, a universalidade do homem aparece necessariamente na universalidade que faz da natureza inteira o seu corpo inorgânico (MARX, 2010, p. 84). Assevera Marx: "A natureza é o corpo inorgânico do homem, a saber, a natureza enquanto ela mesma não é corpo humano" (MARX, 2010, p. 84). Pois, o autor esclarece a relação entre o homem e a natureza, quando explica:

[...] O homem vive da natureza significa: a natureza é o seu corpo, com o qual ele tem de ficar num processo contínuo para não morrer. Que a vida física e mental do homem está interconectada com a natureza não tem outro sentido senão que a natureza está interconectada consigo mesma, pois o homem é uma parte da natureza. (MARX, 2010, p. 84).

Assim, a atividade vital, a vida produtiva mesma não aparece ao homem apenas como meio para a satisfação de uma carência, a necessidade de manutenção de existência física, tal como aparece no capitalismo. Para Marx, portanto, “A vida produtiva é, porém, a vida genérica. É a vida engendradora de vida" (MARX, 2010, p. 84).

$\mathrm{O}$ autor defende que a diferença primordial entre o homem e o animal se encontra no modo da atividade vital, isto é, na maneira como a atividade vital é realizada, pois na atividade vital encontra-se o caráter inteiro de uma espécie, ou seja, seu caráter genérico. Portanto, para este pensador alemão, a atividade consciente livre é o caráter genérico do homem (MARX, 2010, p. 84).

O animal, de acordo com Marx, é imediatamente um com a sua atividade vital. Não se distingue dela. É ela. "O homem faz da sua atividade vital mesma um objeto da sua vontade e da sua consciência. Ele tem atividade vital consciente" (MARX, 2010, p. 84). Assim, a atividade vital consciente distingue o 
homem imediatamente da atividade vital do animal, pois este último não possui atividade vital consciente e livre. Logo, diante de tal exposição, Marx assevera que justamente por isso, o homem é um ser genérico.

Entendemos, portanto, que a atividade vital consciente livre é uma característica específica do ser humano e que, neste sentido, possui uma articulação com a concepção de educação em Marx. Pois, o homem necessita da educação para se desenvolver e se distanciar das limitações da natureza, visto que o homem é um ser consciente. Assim, mesmo possuindo atividade vital diferente da atividade vital dos animais, o homem precisa, necessariamente, de um processo de socialização (educação) para o desenvolvimento pleno das suas capacidades.

Ao argumentar sobre o caráter genérico do homem, sobre a sua essência, Marx não pensa o homem individual, isolado, sem articulação com a sociedade, mas, ao contrário, o homem, para Marx, é ser real, concreto, vivo, em relação direta com outros homens em sociedade. Na nossa compreensão, não haveria sentido falar sobre um processo de educação se o homem não necessitasse do convívio e da socialização com outros homens para tornar-se homem numa sociedade.

Defendemos, sem hesitação, que a educação, no pensamento de Marx, na qualidade de atividade formativa dos homens, participa diretamente do processo de retomada consciente e responsável do caráter genérico do homem para a construção de um mundo prático-efetivo tendo como base a autoatividade humana livre.

\section{Considerações finais}

Após a realização da pesquisa, identificamos que durante o período de 1844 a 1848, a partir dos estudos das obras, a saber: Manuscritos econômico-filosóficos (1844), A ideologia alemã (1845-1846), e Manifesto Comunista (1848), Marx entende a educação como um processo de desenvolvimento das capacidades físicas, intelectuais e moral do ser humano em geral, uma educação de desenvolvimento e aperfeiçoamento

pleno das capacidades humanas. É importante, destacar, ainda, que não se trata de uma educação meramente formal sem articulação com as relações sociais. Para Marx a educação tem suas raízes nas relações sociais, ou melhor, a educação é indissociável da sociedade, pois constitui-se social e historicamente em articulação com a categoria trabalho, na acepção de atividade constitutiva e formativa do ser social. Tal concepção é a planta fundamental para a construção de uma nova sociedade que tem como ponto de partida a crítica consciente das contradições reais do capitalismo e a atividade prática revolucionária para a transformação da realidade existente. Isto posto, percebe-se que tal transformação parte do existente e não do idealizado, ou seja, parte de uma intervenção responsável e consciente dos homens sobre a realidade material para uma transformação radical das condições dadas anteriormente que sustentam a sociedade do capital.

Defendemos, portanto, que a educação assume uma importância no conjunto das obras analisadas, pois ela é responsável não apenas pela transmissão dos valores, das técnicas, ou melhor, da 
cultura, mas, principalmente, pelo desenvolvimento humano, isto é, pelo processo de formação do próprio homem.

\section{Referências:}

BRANDÃO, Carlos Rodrigues. O que é educação. 28 ed. São Paulo: Brasiliense, 1993.

CHAGAS, Eduardo F. A Natureza Dúplice do Trabalho em Marx: Trabalho Útil-Concreto e Trabalho Abstrato. In: Trabalho, Educação, Estado e a Crítica Marxista. Fortaleza: Edições UFC, 2009, p.2536.

KONDER, Leandro. Marxismo e alienação: contribuição para um estudo do conceito marxista de alienação. São Paulo; Expressão Popular, 2009.

LOMBARDI, José Claudinei. SAVIANI, Dermeval. (org.). Marxismo e educação. 2 ed. Campinas, SP: Autores Associados: HISTEDBR, 2008.

LUKÁCS, György. IV. Os princípios ontológicos fundamentais de Marx. In: Para uma ontologia do ser social I. Tradução: Carlos Nelson Coutinho; Mário Duayer e Nélio Schneider. 2012. p. 196-294. Disponível em: <https:// philarchive.org/archive/JOHANO-5 > Acesso em: 08 jan. 2019.

MANACORDA, Mario Alighiero. Marx e a pedagogia moderna. [tradução Newton Ramos-deOliveira]. Campinas, SP: Editora Alínea, 2007.

MARX, Karl; ENGELS, Friedrich. Textos sobre educação e Ensino. Campinas, São Paulo: Nevegando, 2011.

MARX, Karl; ENGELS, Friedrich. A ideologia alemã: Crítica da mais recente filosofia alemã em seus representantes Feuerbach, B. Bauer e Stirner, e do socialismo alemão em seus diferentes profetas, [18451846]. Tradução: Rubens Enderle. São Paulo: Boitempo, 2007.

MARX, Karl. ENGELS, Friedrich. Manifesto comunista. Organização e introdução de Osvaldo Coggiola. São Paulo. Editorial Boitempo. 2007.

MARX, Karl. Manuscritos econômico-filosóficos. Tradução, apresentação e notas de Jesus Ranieri. São Paulo: Boitempo Editorial. 2010.

MÉSZÁROS, Istvan. A educação para além do capital. Tradução Isa Tavares. 2 ed. São Paulo: Boitempo, 2008.

MÉSZÁROS, Istvan. A teoria da alienação em Marx. Tradução de Isa Tavares. São Paulo: Boitempo, 2006.

NOGUEIRA, Maria Alice. Educação, saber, produção em Marx e Engels. 2 ed. São Paulo: Cortez, 1993.

RANIERI, Jesus. A câmara escura. Alienação e estranhamento em Marx. São Paulo: Boitempo, 2001.

SUCHODOLSKI, Bogdan. Teoria marxista da educação. Tradução de Maria Carlota Melo. Editorial Estampa, Lisboa, 1976.

VÁZQUEZ, Adolfo Sánchez. Filosofia da práxis. Tradução de Luiz Fernando Cardoso. $2^{\mathrm{a}}$ ed. Rio de Janeiro: Paz e Terra, 1977.

Notas

${ }^{1}$ Doutorando em Educação pelo Programa de Pós-Graduação em Educação da Universidade Estadual do Ceará (PPGE-UECE). Mestre em Educação pelo Programa de Pós-Graduação em Educação da Universidade Federal do Ceará (PPGE-UFC). Possui 
graduação em História pela Universidade Estadual Vale do Acaraú (2012). Estudante do curso de Bacharelado em Filosofia pela Universidade Federal do Ceará (2019). Membro do Grupo de Estudos Marxistas (GEM/UFC), vinculado ao Eixo Marxismo, Teoria Crítica e Filosofia da Educação do Programa de Pós-graduação em Educação da Universidade Federal do Ceará (PPGEUFC). Membro do Grupo de Pesquisa Ontologia do Ser Social, História, Educação e Emancipação Humana (GPOSSHE). Currículo Lattes: http://lattes.cnpq.br/5409036944293538. Orcid: https://orcid.org/0000-0002-1036-8381. E-mail: salvadoralmeida002@gmail.com.

2 Doutor em Educação pela Universidade Federal do Ceará (2007). Em 2016-2017 fez estágio pós-doutoral em Filosofia Política na Universidade Federal do Ceará (UFC). Mestre Em Educação Brasileira pela Universidade Federal do Ceará (2000). Graduado em Direito pela Universidade Federal do Ceará (1996). Atualmente é professor adjunto da Faculdade de Educação de Itapipoca da Universidade Estadual do Ceará (FACEDI/UECE), professor do Programa de pós-graduação em Educação da Universidade Estadual do Ceará (PPGE/UECE), professor do mestrado acadêmico em Serviço Social, Trabalho e Questão Social da Universidade Estadual do Ceará (MASS/UECE), membro do Conselho editorial da Revista Outubro (São Paulo) e Coordenadorgeral do Instituto de Estudos e Pesquisas do Movimento Operário. Líder do Grupo de Pesquisa Ontologia do Ser Social, História, Educação e Emancipação Humana (GPOSSHE). Currículo Lattes: http://lattes.cnpq.br/7944751664196175. Orcid: https://orcid.org/0000-0002-8357-4557. E-mail: frederico.costa@uece.br.

${ }^{3}$ Concordamos com Lombardi, "Marx e Engels nunca escreveram um texto - folheto, livro ou artigo - dedicado expressamente ao tema do ensino e educação. Suas referências sobre estas questões aparecem separadas ao longo de sua obra, tanto nos escritos de sua juventude como nos de sua maturidade, tanto nos Manuscritos como em O Capital. A partir de sua produção não é possível "levantar" um sistema pedagógico ou educativo completo e elaborado" (LOMBARDI, 2011, p. 6). Porém, afirmamos que é possível a partir das obras de Marx e Engels colaborar com o debate no campo educacional, ou seja, discutir com a pedagogia do nosso tempo, pois as passagens ao longo das obras em articulação com os conceitos e categorias que formam o legado teórico destes pensadores revelam uma preocupação com o desenvolvimento pleno das capacidades humanas e com uma forma de sociedade criada pelo homem e para o homem. Tal forma de sociedade não se apresenta na atual forma de organização social. Nesta, o trabalhador se torna também uma mercadoria, o valor do trabalhador aumenta ou diminui na medida em que aumenta ou diminui a procura pelo trabalhador com a finalidade de fazer uso de sua força de trabalho. Pois, na sociedade capitalista, de acordo com Marx, "O trabalhador se torna tanto mais pobre quanto mais riqueza produz, quanto mais a sua produção aumenta em poder e extensão." (MARX, 2010, p. 80).

4 "A crítica à ordem social constituída e à sua classe dominante, a convicção de que a tarefa do pensamento humano consiste em desmascarar o mundo burguês e cooperar com a revolução que se anuncia e devolve a dignidade humana, tudo isso representa uma parte da luta política de Marx. [...]” (SUCHODOLSKI, 1976, p. 21). Neste sentido, afirma Suchodolski (1976), que Marx observou o mundo com os olhos de homem social e determinou que o mundo não é absolutamente racional e não se subordina aos ideais humanos objetivos; muita luta é necessária para realizar tudo o que moral e historicamente é correto.

5 Segundo Marx e Engels, "A primeira forma de propriedade, tanto no mundo antigo como na Idade Média, é a propriedade tribal, condicionada entre os romanos principalmente pela guerra e entre os germanos pela pecuária. Entre os povos antigos, porque numa mesma cidade coabitavam muitas tribos, a propriedade tribal aparece como propriedade do Estado e o direito do indivíduo sobre ela como simples possessio, que, todavia, se limita, assim como a propriedade tribal em geral, tão somente à propriedade da terra. A propriedade privada propriamente dita começa, tanto entre os antigos como entre os povos modernos, com a propriedade mobiliária - (escravidão e comunidade) (dominium ex jure Quiritium). Entre os povos originados da Idade Média, a propriedade tribal desenvolve-se passando por diferentes fases - propriedade feudal da terra, propriedade mobiliária corporativa, capital manufatureiro - até chegar ao capital moderno, condicionado pela grande indústria e pela concorrência universal, quer dizer, até chegar à propriedade privada pura, que se despiu de toda aparência de comunidade e suprimiu toda influência do Estado sobre o desenvolvimento da propriedade. A essa propriedade privada moderna corresponde o Estado moderno, que, comprado progressivamente pelos proprietários privados por meio dos impostos, cai plenamente sob o domínio destes pelo sistema de dívida pública, e cuja existência, tal como se manifesta na alta e na baixa dos papéis estatais na bolsa, tornou-se inteiramente dependente do crédito comercial que lhe é concedido pelos proprietários privados, os burgueses. A burguesia, por ser uma classe, não mais um estamento, é forçada a organizar-se nacionalmente, e não mais localmente, e a dar a seu interesse médio uma forma geral. [...]. (MARX; ENGELS, 2007, p.74).

6 “[...] Nos seus poderosos estudos, artigos e discursos, Marx mostra concretamente qual é a situação material dos homens no capitalismo em desenvolvimento e o que será no futuro. Com séria exatidão, que expressa o rigor dos juízos científicos e morais, Marx expõe as desumanas condições de vida a que o capitalismo submete os seus escravos. Também mostra como o egoísmo da propriedade e o meio da catástrofe condicionam a classe dominante e exploradora. Estas questões históricas morais e humanitárias na caracterização das relações existentes aparecem muito claras nas análises de Marx. Questões que se referem à situação dos homens na época capitalista e que possuem uma grande importância para a pedagogia." (SUCHODOLSKI, 1976, 121).

${ }^{7}$ Segundo Maria Alice Nogueira, o princípio da combinação estudos-trabalhos não foi, por assim dizer, criado por Marx e Engels. Em realidade, esta tese já havia sido enunciada no curso do desenvolvimento do pensamento pedagógico sobretudo pelos socialistas utopistas do século XIX, em particular pelo francês Charles Fourier (1772-1837) e pelo inglês Robert Owen (17711875). Tendo este último inspirado diretamente Marx nesse campo, tanto por suas ideias quanto com suas experiências concretas (NOGUEIRA, 1993, p. 100). 